\title{
DIREITO À SAÚDE, TEORIAS NEGADORAS, LOTERIA E MÍNIMO DECENTE
}

Edith Maria Barbosa Ramos

Doutora em Políticas Públicas pela Universidade Federal do Maranhão. Mestre em Direito pela Universidade Federal de Minas Gerais. Graduada em Direito pela Universidade Federal do Maranhão. Professora Adjunta do Departamento de Direito e do Programa de Mestrado em Direito e Instituições do Sistema de Justiça da UFMA. Professora e Pesquisadora da Universidade do CEUMA. Professora do IMEC. Coordenadora do Núcleo de Estudos em Direito Sanitário - NEDISA/UFMA.

\section{Paulo Roberto Barbosa Ramos}

Pós-Doutor em Direito Constitucional pela Universidade de Granada - Espanha. Doutor em Direito Constitucional pela Pontifícia Universidade Católica de São Paulo. Mestrado em Direito pela Universidade Federal de Santa Catarina. Graduado em Direito pela Universidade Federal do Maranhão. Professor Associado e Coordenador do Mestrado em Direito da Universidade Federal do Maranhão. Professor e Pesquisador da Universidade do CEUMA. Promotor de Justiça do Estado do Maranhão. Bolsista Produtividade da FAPEMA.

\section{Resumo}

Abordam-se as teorias negadoras do direito à saúde com o objetivo de evidenciar a fragilidade das argumentaçôes e demonstrar a possibilidade de se construir uma justificação metajurídica e ética para a garantia do direito à saúde. Destaca-se a complexidade do direito à saúde e a universalidade de sua titularidade, assim como problematiza-se a identificação do direito à saúde com o direito à assistência social. Analisam-se as teorias de negação do direito à saúde a partir de uma proposta que se apresenta libertariana. Destaca-se a discussão sobre as relaçóes propostas por essa teoria entre o direito à saúde e o direito de propriedade, com o objetivo de justificar a configuração de um estado mínimo. Coloca-se em evidência a ideia de loterias natural e social, o dever de beneficência e a ideia de mínimo decente para introduzir uma reflexáo sobre o mercado da saúde.

\section{Palavras-chave}

Saúde; Teorias negadoras; Mínimo descente. 


\section{Abstract}

It approaches the theory that deny the right to health in order to highlight the fragility of arguments and demonstrate the ability to build a ethical justification for guaranteeing the right to health. Highlights the complexity of the right to health and the universality of their ownership, as well as discusses the identification of the right to health with the right to social assistance. It analyzes the theories of denial of the right to health from a proposal that presents libertarian. Noteworthy is the discussion on the relations proposed by this theory, between the right to health and the right to property, in order to justify the setting of a minimal state. We put in evidence the idea of natural and social lotteries, the duty of beneficence and the idea of decent minimum, to introduce a reflection on the health market.

\section{Key words}

Health; Theories of denial; Decent minimum.

\section{Introdução}

O presente artigo objetiva problematizar as teorias negadoras do direito à saúde. Para tanto, apresentam-se dois argumentos que demonstram a fragilidade de tal concepçáo, quais sejam: que tem sentido conceitual falar-se de direito à saúde; e que o direito à saúde é um direito justificado, entendendo sua justificação como metajurídica e ética.

Discute-se, também, que o direito à saúde é um direito complexo, pois expressa uma série de elementos distintos, embora conectados entre si. Em seguida, a partir desta constatação, objetiva-se demonstrar que o direito à saúde é um direito que deve ser concebido como universal em sua titularidade. Problematiza-se a identificação do direito à saúde com o direito à assistência à saúde. Ainda póe-se em análise a identificação do direito à saúde com um direito de negaçâo, ou seja, de o indivíduo não ser lesado em sua saúde.

Observa-se que num contexto de cortes crescentes no setor da atenção à saúde, de avanço notável de novas tecnologias e de uma suposta crise do Estado Social, a questáo da justificação do direito à saúde chama atenção, principalmente quando o debate aborda o seu alcance, os seus limites e as formas em que estaria justificado fornecer - ou ainda racionar - os recursos em saúde. Por isso, não é de se estranhar a crescente expansão e incremento da literatura mundial sobre as questóes sanitárias.

Inicialmente analisar-se-á as teorias de negação do direito à saúde desenvolvidas a partir de uma proposta que se apresenta como libertariana. Discute-se a justificaçáo do direito à saúde pelo princípio da autonomia/liberdade, em especial, por meio do direito de propriedade. Objetiva-se demonstrar que essa proposta se preocupa fundamentalmente 
em justificar e traçar o significado do direito de propriedade. Assim, o único Estado que está justificado por meio da presente teoria é o Estado Minimo. Analisa-se a possibilidade de justificação das políticas de saúde pública nessa perspectiva, assim, como póem-se em debate a ideia de que a doença é uma falta de sorte, mas não uma injustiça.

Para alcançar os objetivos propostos o trabalho foi dividido em três capítulos, quais sejam: problematização das teorias negadoras do direito à saúde; estado mínimo, loteria social e direito à saúde e, dever de beneficência e decent minimum.

No primeiro capítulo, como mencionado acima, abordam-se as teorias negadoras do direito à saúde com o objetivo de evidenciar a fragilidade das argumentaçóes e demonstrar a possibilidade de se construir uma justificação metajurídica e ética para a garantia do direito à saúde. Destaca-se a complexidade do direito à saúde e a universalidade de sua titularidade, assim como, problematiza-se a identificação do direito à saúde com o direito à assistência social.

No segundo capítulo analisa-se as teorias de negação do direito à saúde a partir de uma proposta que se apresenta libertariana. Destaca-se a discussão sobre as relaçôes, propostas por essa teoria, entre o direito à saúde e o direito de propriedade, com o objetivo de justificar a configuração de um estado mínimo. Coloca-se em evidência a ideia de loterias natural e social de Engelhardt (1995).

No último capítulo analisa-se o dever de beneficência e a ideia de mínimo decente de Buchanan, para introduzir uma reflexão sobre o mercado da saúde.

Para construçáo do presente artigo utilizou-se o método analítico, cuja aproximação das teorias da negadoras caminharam de um plano abrangente para constataçóes particulares com o objetivo de problematizar a justificação do direito à saúde. Desenvolveu-se procedimento de pesquisa monográfico, com a finalidade de evidenciar a falta de solidez das teorias libertarianas, assim como abordaram-se diferentes teorias que pretendiam ultrapassa tal perspectiva, mas que caíram na armadilha do individualismo e do mercado. Foi utilizada a técnica de pesquisa bibliográfica. Deve-se destacar que o presente artigo é parte de pesquisa desenvolvida no âmbito do Núcleo de Estudos em Direito Sanitário e do Núcleo de Estudos de Direito Constitucional da Universidade Federal do Maranhão, num processo articulado e interdisciplinar de atuação científica.

\section{Problematização das Teorias Negadoras do Direito à Saúde}

Diante das teorias negadoras, ou seja, aquelas teorias que negam que se possa falar de um direito à saúde, devem-se apresentar dois argumentos que demonstram a fragilidade de tal concepção, quais sejam: que tem sentido conceitual falar-se de direito à saúde; e que o direito à saúde é um direito justificado, entendendo sua justificação como metajurídica 
e ética, configurando-se esta perspectiva como suficiente para resguardar um direito fundamental à proteção da saúde.

Em seguida, deve-se assumir que o direito à saúde é um direito complexo, pois expressa uma série de elementos distintos, embora conectados entre si. Entre eles estão no mínimo: o direito que tem o indivíduo de não sofrer danos, em sua saúde, provocados por terceiros, sejam pessoas físicas ou jurídicas, públicas ou privadas; o direito a que o estado promova uma série de medidas e políticas de proteção e promoção da saúde pública, meio ambiente e seguridade social e que sejam criadas condiçóes para que a saúde das pessoas não seja ameaçada; e o direito à assistência sanitária. Este ponto é importante, pois de alguma forma as outras condiçóes dele derivam.

Em terceiro lugar, efetivamente, se o direito à saúde abarca todos esses elementos, não resta dúvida de que este direito deve ser concebido como universal em sua titularidade. A questão torna-se mais complexa quando se identifica o direito à saúde ao direito à assistência à saúde. Para alguns, o direito à assistência à saúde não tem caráter universal (AÑÓN, 2009). No entanto, Añón (2009) argumenta que a redução do direito à saúde ao direito à assistência à saúde não afeta a universalidade do direito à saúde já que deve ser concebido como universal em todas as suas vertentes, inclusive na perspectiva da assistência à saúde.

Fala-se, geralmente, de direito à saúde, mas a própria denominação desse direito está longe de suscitar consenso. Assim, pode-se ressaltar, de acordo com Añón, no mínimo seis possibilidades de apresentação desse direito, quais sejam:

[...] direito à saúde, direito à assistência sanitária, direito à proteção da saúde, direito a gozar de um nível adequado de saúde ou, paradoxalmente, as expressōes aparentemente contraditórias: direito ao máximo nível possível de saúde e o direito ao mínimo decente de assistência sanitária (AÑÓN, 2009, p. 37).

Tomadas em suas formulações estritas, cada uma dessas denominações têm alcance e significado bastante diversos. Examine-se, por exemplo, os textos e declaraçóes jurídicas de âmbito internacional em que se reconhece o direito à saúde. As declaraçóes internacionais de direitos humanos não só constituem normas válidas - Declaração de 1948, por exemplo, como permitiram que o direito à saúde fosse alçado à categoria de direito fundamental, tal como ainda, para exemplificar, o artigo $6^{\circ}$ da Constituição da República Federativa Brasileira de 1988. Além disso, as declaraçóes internacionais constituem verdadeiros standards de legitimidade do poder dos estados, pois são uma referência iniludível e uma diretriz inquestionável para a compreensão do conteúdo dos direitos humanos. Faz-se referência, exemplificativamente, ao artigo 25 da Declaração Universal de Direitos Humanos de 1948, ao Pacto Internacional de Direitos Econômicos, Sociais e Culturais 
de 1966 em seu artigo 12, à Convenção sobre os Direitos das Crianças em seu artigo 24, entre outros.

Deve-se observar a formulação prevista no preâmbulo da Constituição da OMS, de 1946, ao asseverar que todos os povos têm direito de "[...] goce del grado máximo de salud que se pueda lograr es uno de los derechos fundamentales de todo ser humano sin distinción de raza, religión, ideología política o condición económica o social.” (OMS, 1946, p. 1).

Chama a atenção a heterogeneidade das formulaçóes, mas também os numerosos elementos que parecem estar reconhecidos nas diferentes declaraçôes. Assim, e isto é muito relevante, o texto da Declaração Universal de Direitos Humanos parece distinguir ao menos três elementos diferentes que devem ser levados em consideração quando se trata do direito à saúde, quais sejam: o direito a um nível de vida adequado que assegure saúde e bem-estar; o direito à assistência médica e serviços sociais básicos; e o direito ao auxílio doença (para suportar a doença na medida em que se pressupóe uma perda dos meios de subsistência - trabalho - por circunstâncias alheias a vontade do indivíduo).

Se se quiser dar relevância à formulação da Declaração Universal de Direitos $\mathrm{Hu}$ manos na configuração desse direito, ter-se-á, ao menos, que constatar determinadas referências fundamentais. Em primeiro lugar, o direito à saúde não é suscetível de uma consideração simplista, pois se apresenta como um direito complexo, por agrupar uma série de elementos de diversos âmbitos. Para Dallari e Nunes Júnior:

Uma das questôes mais elementares - e, contraditoriamente, mais complexas - no Direito Sanitário é a formulação de um conceito jurídico de saúde. Isso porque, embora já existam diversos juízos sobre o tema, ainda não houve um que granjeasse, senão o consenso, ao menos a hegemonia na doutrina. Nesse ambiente de dilemas e dúvidas, podemos encontrar, no entanto, alguns lugares comuns, de onde partem, ou partiram, quase todos os esforços conceituais em relação ao assunto. O primeiro deles advém da acepção com que o termo é ordinariamente empregado: saúde como ausência manifesta de doença. Com efeito, a descoberta dos germes causadores de doenças e o seu subsequente isolamento, que possibilitou o desenvolvimento de remédios específicos, somada ao verdadeiro culto à ciência, predominante no século vinte, induziu a disseminação do conceito de saúde como ausência de doenças. As drogas aperfeiçoadas, adequadamente empregadas, resultavam na cura de várias doenças, salvando muitas vidas. Parece evidente, entretanto, que a ausência de doença, embora expresse um fator importante do estado de saúde, não o esgota, pois diversos outros aspectos devem ser considerados, como, por exemplo, o bem-estar psíquico do indivíduo. A insuficiência do conceito, contudo, não lhe subtrai importância, pois, se de um lado, padece da falta de amplitude, de outro, apresenta a virtude da precisão, o que serve, ao menos, 
para exprimir um núcleo claro e preciso dentro de um conteúdo mais abrangente. Em outras palavras, como sempre haverá algum espaço de indeterminação, estremar-se conteúdos de clareza e determinação constitui instrumento hermenêutico dos mais relevantes (DALLARI; NUNES JÚNIOR, 2010, p. 7).

Assim, a consideração do direito à saúde dos indivíduos e sua proteção aparece fortemente vinculada com aspectos relativos ao nível e as condições de vida da população. Além disso, os serviços médicos de saúde aparecem apenas como um dos elementos integrantes do direito à saúde, mas não o único. $\mathrm{O}$ auxílio doença figura como um elemento autônomo desvinculado da assistência médica e este auxílio configurando-se como um seguro destinado a suportar as situações de infortúnio do trabalhador. Ou seja, o auxílio doença deve assegurar a subsistência do trabalhador e sua família nos períodos em que o trabalhador esteja impedido de desenvolver regularmente sua atividade laboral.

Esta perspectiva desvincula o direito à assistência à saúde do seguro obrigatório para todos os trabalhadores e parece fortalecer a ideia de que o direito aos serviços de saúde não estariam necessariamente vinculados com a situação de trabalhador ativo, embora historicamente esta tenha sido sua origem. A temática dos serviços de saúde tem ganhado uma tendência de universalidade, e desta forma, de fornecimento incondicionado.

Apesar de todo o conjunto de argumentaçôes acima expostas, a configuração do direito à saúde, ainda, está distante de uma unanimidade. Para os críticos da expressão direito à saúde, esta terminologia é uma forma abreviada e pouco precisa de se referir ao direito de proteção à saúde, já que a expressão direito à saúde, entendida estritamente, não teria sentido, vindo a significar no mínimo um direito a não estar doente, o que está fora das possibilidades jurídicas, ou seja, o direito não pode garantir um resultado que está fora do alcance humano, apenas pode garantir a utilização de certos instrumentos para a proteção e recuperação da saúde.

$\mathrm{Na}$ realidade seria um direito à proteção no sentido em que é um direito a que se estabelece por parte do Estado - uma série de medidas que permitem que a saúde dos cidadãos seja promovida ou reparada. Embora seja impossível garantir os resultados, não parece que este argumento seja concludente quanto ao uso da expressão direito à saúde. É o que observa Toebes (2001), não sem certa ironia, ao dizer que o direito à vida pretende poder garantir a vida eterna. Podem-se dizer coisas similares de muitos outros direitos, como o direito à segurança, o direito à educação ou outros direitos sociais, e não há contestação quanto à utilização dessas expressões em relação a estes últimos direitos.

A denominação direito à saúde é seguramente a mais utilizada no âmbito das Nações Unidas. Assim, utilizar-se-á a expressão direito à saúde em geral, já que esta parece ser a mais coerente com os textos internacionais. Os principais documentos internacionais 
vinculam a expressão direito à saúde não apenas a assistência à saúde, mas também a todas as condiçóes necessárias para a saúde, como o acesso à água potável, o meio ambiental, o meio ambiente do trabalhador, dentre outras (TOEBES, 2001).

Em todo caso, se se quiser atender as exigências apresentadas anteriormente sobre a necessidade de especificar a expressão para assinalar que o direito não pode garantir um resultado, pode-se afirmar que a expressão direito à proteção à saúde é a opção mais adequada, embora tenha o grave inconveniente de sugerir uma certa identidade reducionista com o direito à assistência à saúde. Daí ressalte-se, como fez Dallari e Nunes Junior (2010) sobre a importância do Preâmbulo da Constituição da Organização Mundial de Saúde, pois nele são enaltecidos outros importantes aspectos da saúde, como a ideia de saúde como um bem coletivo.

Com efeito, tomando-se como relevante a formulação e as implicações da Declaração Universal de Direitos Humanos de 1948 parece que se tem um primeiro elemento de análise. Se o direito de que se está falando se trata de um direito complexo (COBREROS MENDAZONA, 1988), parece melhor referir-se a um direito à proteção da saúde ou de um direito à saúde e não de um direito de assistência à saúde, que é apenas mais um dos elementos que estão incluídos no direito de proteção à saúde. Assim, por exemplo, Gavín (1989), referindo-se ao caso da configuração do direito à proteção da saúde afirma que este se projeta em três direçóes, que constituem outros tantos aspectos do direito: a) direito à proteção da saúde como direito de todo cidadão as prestaçôes de saúde do Estado; b) direito à proteção da saúde como direito subjetivo em relação à atividade dos poderes públicos para proteger a salubridade pública; e c) direito de proteção à saúde como direito de cada pessoa a que sua própria saúde não seja ameaçada nem lesionada por açóes externas, realizadas por qualquer sujeito público ou privado.

Apesar de todas essas considerações, alguns autores teimam em optar pela expressão direito de assistência à saúde. Não resta dúvida de que este é um elemento essencial do direito à saúde, mas não é o único e nem o mais importante. Além disso, pode-se analisar que o debate sobre a temática da saúde tem, infelizmente, se concentrado nesta dimensão. Principalmente, devido às grandes dificuldades teóricas que o direito à saúde apresenta, tanto do ponto de vista de sua justificação, quanto na sua configuração jurídica e na sua garantia. Esta questão é fortalecida tendo em vista que o direito à saúde se configura como um direito social de prestação, que exige uma atividade positiva do estado.

Dar prioridade ao aspecto de assistência à saúde tenderia a justificar o direito à saúde num aspecto teórico extremamente problemático, daria destaque apenas à perspectiva econômica e deixaria todos os outros aspectos extremamente empobrecidos. Entre os que preferem falar de direito à assistência médica, afirmam que esta é a parte mais importante do direito à saúde. 
González (1999) utiliza a expressão direito à atenção à saúde, entendendo por esta o oferecimento de serviços destinados a prevenir, promover ou recuperar a saúde. Para este autor, tal caracterização do direito teria duas vantagens: a) referir o direito à saúde como direito à atençâo à saúde evitaria ter que conceituar saúde, tarefa que pode resultar prejudicial para efetiva realização do direito, dadas as dificuldades e intermináveis discussóes a que daria lugar obter uma definição prévia de saúde; e b) teria a ver com o paradoxo de se falar direito à atenção à saúde e direito à saúde. Em tal caso se a saúde de uma pessoa se deteriora sem qualquer intervenção, nem de forma direita nem de forma indireta, resultaria difícil saber se e em que sentido se haveria violado este direito.

Não obstante, aos efeitos da fundamentação do direito, esta tem sido uma questão objeto de debate. Assim, a partir de determinadas concepçóes e teorias da justiça, quando se compreende a saúde ou a doença como uma mera circunstância, como uma espécie de loteria natural independente de consideraçôes sobre a estrutura social ou institucional, a ausência de saúde não poderia ser considerada como uma situação de injustiça e não seria problema da sociedade, pois a coletividade não poderia ser responsabilizada pela doença das pessoas.

No que se refere à primeira questão, não ter que contar com uma definição prévia de saúde talvez seja efetivamente uma vantagem porque as definições de saúde são incompletas, sofrem certa indefinição ou são tão amplas que parecem ser pouco operativas. A definição de saúde mais conhecida e citada é a da Organização Mundial de Saúde. Esta definição foi aprovada em 1948 e significativamente - como a própria OMS normalmente adverte - não tem sido emendada desde então. Como já mencionado, a OMS define saúde "[...] como um estado completo de bem-estar físico, mental e social e não meramente ausência de doença." (OMS, 1946, p. 2).

Efetivamente, as críticas apresentadas à definição de saúde da OMS são muito duras e em parte justificadas. Assim, por exemplo, para Gracia (1988), se se tomasse esta definição ao pé da letra, seria preciso medicalizar os orçamentos públicos dos estados e dedicá-los exclusivamente à assistência à saúde.

Cortina (1998), por sua parte comunga desta crítica, considerando, além disso, que a proposta da OMS, não somente seria pouco realista, bem como seria suscetível de criar enormes frustraçóes na medida em que nenhuma sociedade poderia conseguir que todos os seus membros gozassem desse perfeito bem-estar físico, mental e social. Em outro sentido, algo diferente, mas também crítico, Berlinguer (2002, p. 175) tem observado que a saúde não é um estado nem é perfeição, mas sim, “[...] es una situación de equilibrio cambiante que ahora podemos desplazar notablemente hacia lo mejor, a diferencia de lo que ocurría en el pasado.”

No entanto, não se acredita que ter que estabelecer um conceito de saúde seja uma desvantagem ou que seja algo impossível. Cortina (1998), mesmo rejeitando a definição 
da OMS, argumenta que é possível caracterizar de forma aceitável o conceito de saúde, para o qual, como para a qualidade de vida, existem certas variáveis objetivas. Apesar de todos os inconvenientes, para Añón (2009) o conceito de saúde da OMS tem algumas vantagens e enfatiza determinados aspectos que não devem ser olvidados. Frente às concepçóes anteriores de saúde, apresenta a vantagem de abandonar a visão puramente medicamentalizada.

Retomando a discussão sobre a validade das teoria negadoras do direito à saúde, em quarto lugar, derivando da complexidade do direito à saúde, Añón (2009) entende que o direito à saúde não se identifica meramente com um direito de negação, ou seja, de o indivíduo não ser lesado em sua saúde. Entende-se que essa perspectiva é uma parte do direito à saúde - conectada com outros direitos, como o direito a integridade física, ou o direito à vida - mas não a única. Assim sendo, seria possível distinguir entre uma vertente negativa e uma vertente positiva do direito à saúde.

Geralmente, parece constituir uma vantagem teórica e prática e, sobretudo, operativa, identificar o direito à saúde com o direito à assistência à saúde. Essa vantagem seria de dois tipos. Por um lado, essa identificação permitiria definir claramente o alcance do direito à saúde (e com ela, também definir as medidas para sua proteção). Por outro lado, permitiria, ainda, postular o direito à saúde sem a necessidade de optar por um conceito de saúde que é de difícil especificação.

Añón (2009) considera, contudo, que estas aparentes vantagens são extremamente obscuras. Por um lado, se é certo que mediante uma configuração restritiva do direito à saúde se pode estreitar o problema, náo está claro por sua vez que isto permitiria determinar o mínimo protegido pelo direito (ao menos sem buscar uma definição de saúde, com o que se perde sua pretensa vantagem). Além disso, limitar o direito à proteção da saúde a um direito à assistência à saúde não oferece melhores possibilidades de garantia do direito, tanto na perspectiva do não cumprimento individual, quanto no âmbito da abstenção geral dos poderes públicos, ou o que é o mesmo, a questão de efetivação de suas garantias (e em geral, os problemas conceituais e sociológicos atribuídos à proteção dos chamados direitos de prestação).

É certo que não ter que optar por estabelecer uma definição de saúde poderia ser vantajoso, em virtude das dificuldades que isto oferece, contudo, não parece fácil - como se tem sugerido - que se possa determinar um mínimo de proteção sem apelar a algum conceito mínimo de saúde. É certo que algumas teorias da justiça propostas desde o liberalismo igualitário têm optado por não elaborar uma teoria das necessidades básicas que indiquem um nível mínimo de saúde, para centralizar a questão nos desejos e preferências do agente, argumentando a necessária proteção da autonomia individual.

Para Añón (2009) é possível falar da existência de um direito à saúde, em oposição às teorias negadoras em dupla perspectiva: do direito à saúde do ponto de vista jurídico e de sua justificação atendendo a consideraçóes metajurídicas. 
De alguma maneira, estas duas perspectivas representam duas formas de responder a pergunta sobre a existência de um direito à saúde. A pergunta sobre a existência de um direito à saúde, assim formulada, parece imprecisa e irrelevante, no entanto, deve-se observar que é fundamental questionar se conceitualmente faz sentido falar-se de um autêntico direito subjetivo à proteção da saúde (para além do fato que distintas constituiçóes e declaraçóes internacionais de direitos falem sobre o direito à saúde) ou, em outro plano, se existe uma pretensão justificada que possa dar lugar ao estabelecimento de um direito subjetivo à saúde.

Dentre estes dois aspectos Añón (2009) aborda como ponto de partida a segunda perspectiva. $\mathrm{O}$ debate sobre a existência de uma justificação metajurídica, de caráter moral ou político a respeito de um direito à saúde, pode parecer irrelevante quando se aponta para existência de um direito à saúde positivado, previsto em constituiçóes e textos internacionais, que o reconhecem como direito subjetivo. E, ainda de forma mais conclusiva, quando se alude a uma série de instituiçóes, de políticas públicas e de ordenamentos normativos que preveem o direito à saúde em diferentes vertentes.

\section{Estado Mínimo, Loteria Social e Direito à Saúde}

Num contexto de cortes crescentes no setor da atenção à saúde, de avanço notável de novas tecnologias e de uma suposta crise do Estado Social (AÑÓN, 2009), a questão da justificação do direito à saúde chama atenção, principalmente, quando o debate aborda o seu alcance, os seus limites e as formas em que estaria justificado fornecer - ou ainda racionar - os recursos em saúde, por isso não é de se estranhar a crescente expansão e incremento da literatura mundial sobre as questôes sanitárias.

Inicialmente analisar-se-á as teorias negativas do direito à saúde desenvolvidas a partir de uma proposta que se apresenta como libertariana. A resposta radical dada à justificação do direito à saúde pelas teorias libertarianas consiste em negar que o direito à saúde possa ser justificado. Posturas deste tipo apresentam, pelo menos, duas teses que precisam ser abordadas, sejam analisadas isolada ou cumulativamente: a) a primeira entende que não é conveniente ou não é possível justificar a saúde em termos de direitos e b) a segunda entende que o direito à saúde (caso se pudesse falar da existência de um direito à saúde) não é um direito autônomo, mas parte de outros direitos, pois se constitui, unicamente, em duas perspectivas, quais sejam: um direito a que a saúde do indivíduo não seja prejudicada por um terceiro (especialmente, pelo estado), posto que é apenas parte do direito à vida ou do direito à integridade física e um direito a possibilidade de adquirir livremente assistência à saúde no mercado.

Essas duas teses não são incompatíveis. Em relação a tese "a”, trata-se de uma negação completa do direito à saúde e de sua possibilidade de justificação. A tese "b”, embora 
admita a expressão direito à saúde, assevera que esta expressão constitui uma mera afirmação retórica, pois reduz ou identifica o direito à saúde a outros direito negativos genéricos.

Nessa perspectiva retórica, somente poder-se-á admitir o dever de custear a assistência à saúde de um indivíduo no caso de o estado ou terceiro ter provocado diretamente o dano à saúde daquele, ou seja, o direito de assistência à saúde surge como uma compensação ou reparação à violação do direito à vida ou à integridade física do sujeito. Sem dúvida, as propostas mais extremadas de negação sobre a existência de um direito à saúde foram constituídas nas propostas libertárias ou libertarianas de autores como Robert Nozick ${ }^{1}$. A proposta libertariana surgiu nos Estados Unidos da América nos anos 1970, inspirada, principalmente, em Friedrich Von Hayek.

Vita esclarece que:

O valor político central, para essa vertente, é uma noção de "liberdade negativa” - o termo foi cunhado por Isaiah Berlin em seu clássico ensaio de 1958, intitulado "Dois conceitos de liberdade" (Berlin,2002) - que tem por foco a não interferência, sobretudo por parte da autoridade política (mesmo se exercida de forma democrática), em direitos de propriedade ou "titularidades" (no sentido em que Nozick em prega este termo) adquiridos por meio de uma cadeia de transaçóes de mercado voluntárias e não fraudulentas. Dessa perspectiva, a justiça tem duas características distintivas: (1) é uma virtude da conduta individual (Hayek, 1976:31-33), não um atributo que possa ser imputado a uma ordem social e política, ou cuja ausência possa ser criticada em uma ordem social e política; e (2) é uma virtude que se exprime por meio de deveres negativos (Hayek, 1976:35-38), tais como "não interfira arbitrariamente na integridade física ou na propriedade de outros", "não descumpra suas promessas e contratos válidos", "não aja de forma desonesta ou fraudulenta", "não impeça uma pessoa de praticar sua religião ou de exprimir seu pensamento e suas opinióes" e assim por diante, e que se impóem como restriçóes não excepcionáveis às linhas de conduta que agentes individuais, privados e públicos, podem escolher. Nozick (1974:28-35) denomina essas injunçôes morais de "concepção side constraints" de direitos individuais. Mas o emprego da linguagem dos direitos, nesse caso, não deixa de ser dúbio, já que a ideia não é que certos direitos devem ser garantidos igualmente a todos, e sim que agentes privados e especialmente públicos estão sujeitos à exigência de se abster de adotar linhas de ação que, por mais socialmente desejáveis que possam ser, tenham o efeito colateral de violar

1 Robert Nozick foi um proeminente filósofo político americano nas décadas de 70 e 80 . Desenvolveu outros trabalhos adicionais, menos influentes nas áreas de epistemologia e teoria da decisão. A sua obra "Anarquia, Estado e Utopia” de 1974 foi uma resposta libertariana para a obra "Uma Teoria da Justiça” de John Rawls, publicada em 1971. 
"titularidades legítimas" (como são definidas pela própria teoria política libertariana). O foco não recai sobre a igualdade de direitos, quaisquer que sejam; a motivação central é o não descumprimento de deveres que incidem sobre a conduta individual (VITA, 2011, p.572).

A proposta libertariana desenvolveu a ideia de Estado Minimo num quadro de capitalismo radical, mas, fundamentalmente, propôs a garantia dos direitos individuais contra a interferência de terceiros, com o objetivo de proteger o valor supremo da liberdade individual, ou como resumiu Arnsperger e Van Parijs:

El punto de partida del pensamiento libertario es la dignidad fundamental de cada persona, que no puede ser burlada en nombre de ningún imperativo colectivo. Esta dignidad reside en el ejercicio soberano de la libertad de elección en el marco de un sistema coherente de derechos. El libertarismo pretende así articular de manera consecuente una idea cuyo atractivo, hoy en día, no cede en nada frente al ideal utilitarista de una sociedad feliz: una sociedad justa es una sociedad libre (ARNSPERGER E VAN PARIJS, 2002, p. 43).

Para esta proposta, se o valor supremo a defender é a liberdade individual, os únicos direitos legítimos são os direitos de não interferência, que protegem a esfera da individualidade. A extensão desta esfera é determinada pelo conjunto do que possui o indivíduo, ou seja, na tradiçẫo de Locke (1978), o direito de propriedade, especialmente, neste caso específico, a propriedade sobre seu próprio corpo.

Desse modo, o principal direito justificado e delimitado pelo princípio da autonomia/liberdade é o direito de propriedade. Por isso, essa proposta se preocupa fundamentalmente em justificar e traçar o significado do direito de propriedade (AÑÓN, 2009). Os indivíduos devem ser livres para usar, gozar e dispor, sem limitações, de suas propriedades. Isto permite que as propriedades sejam legitimamente transferidas de um indivíduo a outro, sempre que houver acordo de vontades. Nenhum estado e nenhum poder coletivo podem legitimamente estabelecer, por meio de instrumentos normativos, restriçóes à liberdade, ao exercício do direito de propriedade e de livre disposição sobre os bens do indivíduo, inclusive sobre si mesmo (AÑÓN, 2009).

Para Vita:

Disso se segue que nada além de um estado comprometido com um estado de direito que converta em obrigaçóes legais as restriçóes morais à ação que garantem a liberdade negativa tal como interpretada anteriormente, com ênfase na não violação de direitos amplos de propriedade, pode se justificar em nome da justiça. É possível que vastas desigualdades socioeconômicas se produzam em uma "sociedade livre". Mesmo sendo lamentável, isso não justifica que a autoridade política empregue a coerção coletiva da sociedade para realizar um padrão de justiça social. Se há 
desigualdades, isso não é produto das intenções ou dos planos de ninguém em particular, e sim de decisóes tomadas de forma descentralizada por agentes individuais que decidem livremente - e são responsáveis pelas consequências das decisōes que tomam - o que fazer com os recursos sobre os quais têm titularidade plena, nisso se incluindo o exercício dos próprios talentos e capacidade produtiva. Ninguém, em particular, muito menos ainda, a sociedade, pode ser responsabilizado pelas desigualdades socioeconômicas que se geram na "ordem espontânea" produzida pelo mercado que Hayek batizou de "catalaxia” (Hayek, 1976:107-132). Esse é um dos sentidos - o de negar a responsabilidade pública - que pode ser atribuído à célebre frase de Margaret Thatcher de que "não há semelhante coisa como a sociedade". E, mais fundamentalmente, a tentativa de realizar um padrão de justiça distributiva na sociedade implica necessariamente a violação de deveres negativos não excepcionáveis, isto é, implica o emprego arbitrário e, portanto, injusto, do poder político (Vita, 2011, p. 573).

Assim, o único estado que está justificado por meio da presente teoria é o Estado Minimo. O Estado Minimo está unicamente preocupado em garantir que a liberdade de cada um seja preservada, ou seja, é um estado garantidor dos direitos de propriedade e repressor de tudo aquilo que macule ou obstaculize o exercício livre do direito de propriedade ${ }^{2}$.

Deve-se advertir que a proposta de um Estado Mínimo, preocupado apenas com a proteção dos direitos de liberdade e propriedade, por mais que sirva como arsenal argumentativo contra os supostos excessos (assistencialistas) do Estado Social (com práticas coativas e violadoras da liberdade $)^{3}$, não pode ser caracterizado como uma opção atualizada de um Estado de caráter liberal-burguês, tal qual existiu historicamente após o processo revolucionário francês.

Segundo Añón (2009) o Estado liberal-burguês histórico assumiu a proteção da salubridade pública, com uma polícia sanitária que não somente podia exigir, eventualmente, ações de caráter coativo, como também o indivíduo poderia exigir, em certas circunstâncias, uma ação positiva por parte do estado para a proteção da saúde coletiva ${ }^{4}$.

2 Segundo a conhecida frase do prefácio da obra Anarquía, Estado y Utopía de R. Nozick: "Mis conclusiones principales sobre el Estado son que un Estado mínimo, limitado a las estrechas funciones de protección contra la violencia, el robó y el fraude, de cumplimiento de contratos, etc., se justifica; que cualquier Estado más extenso violaría el derecho d ellas personas de no ser obligadas a hacer ciertas cosas y, por tanto, no se justifica; que el Estado mínimo es inspirador; así como correcto. Dos implicaciones notables son que el Estado no puede usar su aparato coactivo con el propósito de hacer que algunos ciudadanos ayuden a otros o para prohibirle a la gente actividades para su propio bien." (NOZICK, Robert. Anarquía, Estado y Utopía. México: FCE, 1990. p. 7).

3 Sobre as críticas liberal-conservadoras ao Estado Social (FERNÁNDEZ, E. Estado, sociedad civil y democracia, en AAVV, valores, derechos y estado a finales del siglo XX. Madrid: Marcial Pons, 1995; OFFE, Claus. Contradicciones en el estado del bienestar. Madrid: Alianza, 1988).

4 Sobre esta questão ver COBREROS MENDAZONA, Eduardo. Los tratamientos sanitários obligatorios y el derecho a la salud. Ońati: Instituto Vasco de Administración Pública, 1988; 
Diante do exposto, segundo o pensamento de Añón (2009) rejeita-se a primeira tese. Passa-se, agora, à análise da tese "b" (em sua dupla versão): como um direito a não ser lesado em sua saúde ou como um direito a adquirir serviços de saúde, ou, ainda, o que é o mesmo, que não existe um direito à saúde, existem apenas direitos de liberdade e propriedade, incluindo neste último a propriedade sobre o próprio corpo (podendo o indivíduo decidir como deve ser seu tratamento, e ainda, que parte de sua renda está disposto a utilizar em tratamento de saúde, em outras palavras, que serviços médicos está disposto a arcar e a que preço). Mesmo assim, observa-se, em qualquer caso, o estado não deve intervir nas questóes de saúde.

Conclui-se que, para essa teoria, nenhuma política de saúde pública ou imposição de seguro público poderiam ser justificadas, pois se o estado patrocinar aos cidadáos o acesso a serviços de saúde estará violando o direito à liberdade e à propriedade, na medida em que, implica uma redistribuição coativa dos bens privados, o que, por sua vez, implica uma imposição ao direito de liberdade/propriedade sem qualquer justificação.

$\mathrm{Na}$ verdade não haveria justificativa nem mesmo para programas de vacinação obrigatória ${ }^{5}$ ou para regulamentação da profissão de medicina. Assim, supóem que os médicos ou hospitais que prestam serviços deficientes ou não corrijam com reparações/indenizaçôes seus erros poderiam ser identificados como estelionatários e, por conseguinte, serem expulsos pelo próprio mercado. No entanto, enquanto não se verificar situação de erro médico/hospitalar ou outras mazelas não estará justificada a tomada de qualquer medida contra a atuação desses médicos e/ou hospitais.

Por fim, se o âmbito da justiça vem definido pelos processos de apropriação das coisas e pela não violação dos direitos de liberdade e propriedade, o fato de uma pessoa adoecer é alheia a questão do direito de liberdade e propriedade, logo não outorga ao estado o dever, nem ao indivíduo o direito de assistência e, muito menos, permite ao estado a apropriação coativa de recursos pertencentes a outras pessoas para custear a saúde pública. Desta feita, Engelhardt (1995) deixa claro a impossibilidade de justificação de um direito à saúde.

De fato, Engelhardt se inspira num argumento próximo às teses libertarianas para negar a existência de um direito à saúde (ENGELHARDT, 1995). Para Engelhardt não se pode falar de direito à saúde. Para não radicalizar, pode-se, para o autor, e em certo sentido, até falar-se do direito à saúde como um direito de não ser lesado por terceiro, mas somente isso (ENGELHARDT, 1995).

AMOEDO SOUTO, Carlos. Poder policial y derecho administrativo. A Coruña: Universidad da Coruña, 2000.

5 Ressalte-se que a proteção da saúde e da salubridade pública são atividades que o Estado Liberal histórico assumiu como própria (STIGLITZ, Joseph Eugene. Le economía del sector público. Barcelona: Bosch, 1995, p. 319). 
Embora alicerçado em argumentos libertários, Engelhardt (1995) oferece uma explicação mais sofisticada que aqueles, pois não se limita a uma mera transposição da proibição de violar os direitos de propriedade de terceiros.

Por isso, a argumentação de Engelhardt (1995) supera, em certa medida, a estrita dimensão das consideraçóes libertarianas. Ele considera que a ideia dos direitos como reivindicaçóes frente a terceiros se situa no plano da justiça. Portanto, supor que existe um direito à saúde, significa supor que existe um imperativo de justiça relativo à saúde, mas isso, no entanto, não significa, por outro lado, dizer que a doença é uma injustiça. Pelo contrário, para o autor a saúde (ou a doença) é uma questão de acaso (sorte ou azar), assim a doença é uma falta de sorte, mas não uma injustiça.

A saúde (ou a falta de saúde) seria o resultado de uma loteria natural: uns gozam de melhor saúde que outros e perdem ou ganham saúde em distintos momentos de sua existência ${ }^{6}$. Além da loteria natural, Engelhardt também fala de uma loteria social, porém esta loteria social, mesmo utilizando-se da expressão social, não está vinculada a ações ou omissóes de terceiros (AÑÓN, 2009). Para ele, as desigualdades entre as pessoas se devem a circunstâncias do acaso, que podem ter um caráter natural ou social, assim como se deveram ao acaso não podem reputar-se como justas ou injustas.

Engelhardt (1995) admite que é difícil traçar uma distinção clara entre a injustiça e o acaso, mas sustenta que este é o único critério adequado para admitir reivindicaçóes legítimas em matéria de saúde: será uma reivindicação legítima a que derive de um dano causado injustamente por terceiro, não uma simples necessidade.

Raciocina da seguinte forma: se se admitir a possibilidade de que as necessidades se convertam em critérios para imposição de demandas perante terceiros, se se admitir a possibilidade de que as necessidades criem direitos, se estará violando a autonomia das pessoas - o núcleo do liberalismo - pois se permitirá ao Estado legitimar medidas coativas frente aos direitos de liberdade e propriedade.

Dos dois tipos de loteria, a natural e a social, a primeira é seguramente a que proporciona o argumento de caráter mais geral (e que também se dirige diretamente a refutar toda pretensão de justificação de um direito à saúde). Já o argumento da loteria social somente funciona no âmbito das teorias libertarianas. Parece inegável que a saúde ou a ausência de saúde tenha algo do acaso: a predisposição genética a uma doença ou a possibilidade de sofrer um acidente imprevisível parecem ser questóes de má sorte.

No entanto, não parece ser legítimo operar uma completa naturalização nesse sentido, embora o fato de que uma pessoa possa nascer no seio de uma família rica ou pobre

6 RAWLS, John. A teoria da Justiça. Brasília, DF: UnB, 1981. Ressalte-se que esta concepção de loteria natural Engelhardt toma da teoria da justiça de Rawls. Contudo, para Rawls a distribuição dos talentos e dons que produzem a loteria natural é moralmente arbitraria e injusta. 
possa se configurar como uma questão de acaso. No entanto, não é uma questão de acaso que existam famílias ricas e pobres, também não é uma questão de acaso que existam desigualdades sociais, ou que essas desigualdades sejam tão abissais ${ }^{7}$.

Isso ocorre exatamente porque a maior ou menor desigualdade depende, em certa medida, da estrutura social das instituiçóes básicas da sociedade. Por isso, o argumento de sustentação da loteria social somente é válido se se aceita o ponto de partida das teorias libertarianas, ou seja, somente se a questão da justiça se reduz ou se limita à proteção de determinados direitos preexistentes.

Em vez disso, se se aceita que a questão da justiça está relacionada com as instituiçóes básicas da sociedade, se se aceita que as instituiçóes básicas da sociedade devem ser, não apenas eficientes, mas justas, já não se poderá admitir que a distribuição da riqueza seja uma mera questão de acaso.

Esta suposição de que as instituições sociais básicas devam ser justas e que esta é sua principal virtude é o ponto de partida da teoria da justiça de John Rawls (1981) e com ele de grande parte da discussão posterior sobre a questão da justiça. Exceto a particular visão libertariana, não parece contrário a concepção liberal (de respeito à autonomia) o fato de que a desigual distribuição dos bens sociais seja temática imprescindível e extremamente relevante para consecução do ideal de justiça, bem como necessidade de consecução de certas medidas de correção social sustentadas em direitos, caracterizados como fundamentais.

Em qualquer caso, ainda se não se admitir o argumento da loteria social - ou se se considera que a loteria social tem um peso relativo nas questóes de saúde - merece maior consideração, neste momento, o argumento da loteria natural. A crítica as teses de Engelhardt podem ser obtidas, segundo Añón (2009), a partir de dois pontos de vista: a) questionar se a saúde (ou a sua ausência) podem ser atribuídas a uma loteria natural e b) questionar a relevância de sua delimitação no campo da justiça, ou seja, quais circunstâncias devidas ao acaso não têm importância para a discussão do âmbito da moral.

Em relação ao primeiro argumento, Añón (2009) admite que o acaso - a loteria natural - é importante para a questão da saúde e apresenta dois exemplos que se poderia atribuir ao puro acaso: o caso de uma doença de caráter hereditário ou um acidente imprevisível. Mas entre esses casos e o de um dano causado por terceiro (a única situação que segundo Engelhardt justifica a possibilidade de recair sobre um terceiro os custos da assistência à saúde) existem, ao menos, outros dois tipos de casos intermediários.

7 Acrescente-se que Nozick, em resposta a algumas críticas recebidas, admite que dado que muitas das transaçôes que precederam a atual estrutura de propriedade foram ou podem ter sido ilegítimas, existe a possibilidade de corrigir essas situaçóes utilizando-se do "princípio da retificação", o que poderia justificar um Estado intervencionista para corrigir tais situaçōes (NOZICK, Robert. Anarquía, Estado y utopía. México: CE, 1990. p. 155). 
Existem, inicialmente, casos em que a loteria natural se modifica por causas sociais, como por exemplo: os hábitos de vida do indivíduo, as condiçôes de higiene, a alimentação, a habitação, a riqueza, o próprio acesso a cuidados de saúde - todas essas questôes influenciam decisivamente a loteria natural.

Deve-se destacar que a esperança de vida não é a mesma nos diversos países, não é a mesma entre as classes sociais. $\mathrm{Na}$ África, por exemplo, se registra uma incidência do HIV-AIDS sem comparação no mundo e isso não depende de nenhuma loteria natural (como não dependem, principalmente, de uma loteria natural o número de mortes em acidentes de trânsito, ou na violência urbana ou por doenças cardíacas na América). Além disso, mesmo dentro dos níveis de saúde e mortalidade aceitáveis para uma sociedade (ou uma classe social) existem fatores que incidem na saúde que não são diretamente causados por um terceiro identificado, mas que não podem ser atribuídos exclusivamente a causas naturais: assim, a deterioração da saúde devido a contaminação e/ou intoxicaçáo alimentares, acidentes e catástrofes coma a do Acidente Radiológico - Césio-137, em Goiânia, Acidente Nuclear em Chernobil etc. Estes exemplos problematizam a possibilidade de definir o que está incluído e o que está fora da loteria natural.

No entanto, segundo Añón (2009), com isso, a pureza da distinção de Engelhardt deixa de ter solidez: sem negar o papel de loteria natural de um lado e chance (se a distribuição de catástrofes naturais ou artificiais) por outro, este não é mais um critério confiável do ponto de vista empírico para fazer a distinção entre o que é injustiça e o que é acaso.

Por outra parte, num terreno tão escorregadio deve ser reconhecido que a delimitação do que é natural e social é, por sua vez, culturalmente construído. Parece ser mais significativo, ainda, questionar a segunda parte da tese "b", qual seja: a delimitação do campo da justiça, baseando-se na relevância ou irrelevância para o discurso moral das circunstâncias devidas ao acaso.

Añón (2009) apresenta diferentes indagações sobre a questão do acaso, entre elas as que seguem: Por que ter-se-ia que excluir do campo da justiça a existência de circunstâncias devidas ao acaso? Por que haver-se-ia de excluir do campo da justiça a existência de circunstâncias que sendo distribuídas aleatoriamente entre as pessoas, sabe-se que serão distribuídas de forma desigual? Por que a distribuição dos riscos haveria de ver-se excluída das considerações da justiça? Deve-se perguntar se não é mais injustiça que acaso a existência de diferenças de expectativas de vida numa sociedade segundo a classe social ou se não é mais injustiça que acaso a mortandade devido a doenças facilmente curáveis ou se não é mais injustiça que acaso a mortalidade devida à inexistência de condiçóes de vida dignas.

Nesse sentido, Hierro (2002, p. 100) observou que: "Lo que se siente como una injusticia no es padecer una determinada enfermedad, sino padecer una enfermedad que 
con un reparto más igualitario de los recursos uno podría haber evitado." A proposta de Engelhardt de considerar irrelevante para configuração da justiça a loteria natural é extremamente criticável. Além disso, pode acabar conduzindo a consequências extremadas, na medida em que a negaçáo de um direito à saúde não significa apenas que não pode haver reivindicação legitima de qualquer tipo de assistência à saúde por parte de qualquer cidadão, assim como, seria ilegítimo qualquer tentativa do estado para organizar um sistema de saúde, para prestar assistência à saúde ou de facilitar qualquer incentivo. Para evitar consequências tão extremas, algumas das propostas negadoras do direito à saúde, entre elas a de Buchanan (1984), consideram legítimas, contudo, e até desejável, certa atividade prestacional do estado.

\section{Dever de Beneficência e Decent Minimum}

O dever de beneficência é a alternativa que Buchanan oferece à negação do direito à assistência à saúde. Buchanan também rechaça a existência de um direito à assistência à saúde. Compartilha da ideia de que se existisse um direito à assistência à saúde (cujas possíveis justificaçóes desconsidera em seus trabalhos) este seria virtualmente ilimitado e em razão disso impossível de ser realizado concretamente.

Este parece ser no fundo a preocupação que sobressai em sua proposta. Seus pontos de partida não são essencialmente libertarianos, mas compartilham em muitos aspectos com este ponto de vista. Seu principal argumento está nas dificuldades das abordagens baseadas em direitos, o que em parte, também, afeta os argumentos libertarianos baseados em direitos de não interferência ou de propriedade (BUCHANAN, 1984).

Em particular, Buchanan não mantém, como fazia Engelhardt, que as necessidades em matéria de saúde sejam irrelevantes ou que não devam preocupar ninguém mais do que aqueles que as sofrem. Coincide com Engelhardt, ao situar as pretensóes em matéria de cuidado da saúde fora do âmbito da justiça (e fora do âmbito dos direitos) e em trazê -las de volta ao âmbito não de um direito à saúde, mas de um dever de beneficência, que justifica um mínimo grau de assistência à saúde.

Buchanan (1984) constata que existe certo consenso em reconhecer um direito a um minimo decente (decent minimum) em matéria de saúde, além de admitir, em sua proposta, que o estado deva realizar uma certa atividade para a proteção da saúde dos cidadãos, na medida em que pode coordenar melhor um esforço conjunto neste sentido. Contudo, este dever é estritamente um dever de beneficência e não uma derivação de um princípio de justiça, e muito menos uma derivação de um direito individual à proteção à saúde.

A vantagem de excluir um autêntico direito é dar limitaçóes ao que se converteria em pretensôes ilimitadas (e dificilmente limitáveis a esta categoria de direito subjetivo). 
Pelo contrário, os deveres de beneficência são certamente obrigatórios (não seria um dever se fosse diferente), mas resulta de uma noção mais aberta e que, sobretudo, deixa a critério do agente (o estado) o momento e o alcance do exercício desse dever. Também, nessa perspectiva teórica não há necessidade de uma justificação tão exigente como de um direito à saúde.

Para Buchanan (1984), a justificação da atuação do Estado passa por sua capacidade para coordenar melhor os esforços conjuntos. Efetivamente, se a beneficência fica isolada a certos indivíduos não há garantia de que seja eficiente, visto que em muitos casos o que seus destinatários precisam exigirá uma ação coordenada de várias pessoas.

$\mathrm{O}$ autor mesmo argumenta que, se necessário, estaria justificada uma ação coercitiva do estado em favor do dever de beneficência mediante dois argumentos (BUCHANAN, 1984): a) uma pessoa que queira atuar caridosamente para promover um mínimo decente de assistência veria que seu esforço sozinho sem o esforço de outras pessoas se perderia, posto que, para o autor, o racional seria dedicar seu esforço caridoso para outros fins, mas se todo o mundo atuasse dessa forma seria impossível somar esforços e b) na medida em que o projeto de mínimo decente de saúde seja mais importante que outros fins a que atribuir o orçamento individual para a caridade, se não for oferecida uma garantia de que não seria um esforço vazio - pelos motivos do primeiro argumento - ninguém que aja racionalmente destinará a este projeto seus fundos, pelo que se diminui a eficácia do esforço.

Buchanan (1984) não crê que reforçar o princípio da beneficência (que em seu esquema é um princípio moral) significa uma atuação perfeccionista do estado, na medida em que é feita para garantir a virtude moral dos cidadãos. Na realidade, forçar o princípio moral somente se justifica se for a única forma de assegurar as contribuiçóes dos demais para alcançar resultados eficazes e evitar que o comportamento racional, mesmo para aqueles que têm o desejo de contribuir (ou destinar suas contribuiçôes terá fins menos eficazes).

A proposta de Buchanan (1984) é criticada de forma precisa por Vidiella em duas linhas de pensamento. A primeira destaca as fragilidades das argumentaçóes propostas por aquele e a segunda critica a tese do decent minimum (VIDIELLA, 2000).

Em relação à primeira questão, a argumentação de Buchanan para a justificação da atuação do estado parte da atuação do estado para assimilar o nível decente de saúde como um bem público, como algo necessário para todos. Contudo, na argumentação de Buchanan (1984) é excluída esta possibilidade, posto que sua construção parte de um dever de caridade para com os necessitados, náo de um dever com caráter geral, ou seja, para todas as pessoas.

Por outro lado, a suposta vantagem de se falar de um dever de beneficência em vez de um direito seria o fato de que não seria tão necessário especificar qual o conteúdo do 
dever. Contudo, uma vez que o estado pode forçar a execução do dever, será necessário definir o conteúdo do dever moral de beneficência no que diz respeito à atuação super-rogatória, com a qual será igualmente necessário estabelecer seus limites e fazê-lo de forma justificada, com o que se tem perdido a pretensa vantagem.

Com respeito à tese do decent minimum, Vidiella (2000) observa que o conceito está construído sobre a ideia de proporcionar um nível adequado de saúde que permita levar uma vida tolerável. Contudo, não está claro que se possa realizar uma divisão entre saúde básica e outras superiores: se alguém necessita de um tratamento excluído do decent minimum isto o conduzirá à morte. Não há, neste caso, uma vida tolerável. Mas talvez como também assinala Vidiella - o problema principal constitui a negativa de Buchanan em situar esta questão no plano da justiça e dos direitos.

Além disso, quando Buchanan (1984) afirma como não relevante tais elementos, sua proposta aparece como um retrocesso, tanto do ponto de vista teórico quanto das conquistas históricas, na medida em que substitui a linguagem do direito pela da beneficência (na visão não muito distante das teses inspiradas em Nozick). Percebe-se, por fim, que esta proposta está vinculada a ideia de Estado Mínimo, na medida em que retira a questão das consideraçóes de justiça, a justificação da proteção do decent minimum.

As posturas examinadas até aqui coincidem em atribuir ao mercado um enorme peso na distribuição dos recursos para a saúde. Não são as únicas nesse sentido. Mesmo sem a perspectiva extremada anterior, também no âmbito do utilitarismo, a questão da saúde continua - na expressão de Arnsperger e Van Parijs (2002, p. 110) “[...] numa presunção em favor do mercado."

A presunção a favor do laissez faire não foi abandonada, embora esteja matizada, tendo em vista as características de um mercado como o que se trata e tendo em conta algumas das críticas mais significativas que sofreram as posturas baseadas num mercado puro, como as que, no fundo, propóem os libertarianos. O refinamento e o raciocínio que introduz o utilitarismo podem levar a justificar uma importante atividade do estado, levando mesmo a propor a imposição de um seguro obrigatório de saúde (o que seria inconcebível do ponto de vista libertário).

Para Arnsperger e Van Parijs (2002), o ponto de partida dos utilitaristas admite que determinadas considerações conduzem à limitação da presunção favorável ao livre mercado e à justificação de uma atuação do estado que imponha a todos um seguro obrigatório. Segundo Añón (2009, p. 110), seguem as consideraçóes que devem ser ressaltadas:

a) la falta de información, la valoración incorrecta o una atención insuficiente hacia las personas que están a nuestro cargo, podría llevar a no contratar seguros que aumentarían el bienestar de las familias. Para evitar el despilfarro de bienestar habría que permitirse ser paternalista para imponer a todos un nivel mínimo de seguro, que podría adoptar diferentes formas; 
b) si el seguro es obligatorio para todos, se pueden cubrir algunos riesgos a un coste que todo el mundo considere que vale la pena, pero que no sería así si el seguro fuera facultativo;

c) el recurso a las atenciones médicas puede producir externalidades positivas, es decir, ventajas para otras personas distintas del beneficiados (piénsese en el caso de vacunación o tratamiento de enfermedades contagiosas). Si el seguro es facultativo, los que no contribuyan no solo se conviertan en "gorrones" y "aprovechados", sino que también producen externalidades negativas.

Contudo, seja com seguros obrigatórios ou não, a suposição de que, pura e simplesmente, o mercado pode fazer uma distribuição de recursos sanitários eficiente e justa (HIERRO, 2002) é questionada por diferentes autores. Mas, além de tais argumentaçóes, as políticas públicas em matéria de saúde e o reconhecimento de um direito à saúde, postas em marcha nos sistemas sanitários de caráter público, resultam da histórica constatação de que as injustiças e as desigualdades existentes, no que se refere à proteção da saúde, não podem ser solucionadas unicamente por critérios mercadológicos. Deve-se ressaltar o que observam Beauchamp e Steinboc (1999, p. 103):

Quizá el modo más directo en el que el modelo de justicia basado en el mercado debilita nuestra resolución de preservar y proteger la vida humana tiene que ver con la libertad primaria que este sistema extiende a todos los individuos y grupos para actuar con obligaciones mínimas de proteger el bien común. A pesar del hecho de que esta regla del autointerés de manera previsible falla en la protección adecuada de la seguridad de nuestro lugares de trabajo, de nuestro medios de transporte, de nuestro ambiente físico, de los bienes que consumimos, o de la equitativa y efectiva distribución de la atención médica, esos fallos han resultado hasta ahora solo en débiles intentos de regulación y control. Esta respuesta se explica en gran medida por la poderosa influencia que la justicia basada en el mercado ejerce sobre nuestra imaginación, reconociendo a todos los individuos la libertad fundamental de que nos dejen tranquilos - incluso si los “individuos" en cuestión son grupos económicos gigantes con enormes capacidades de generar enormes perjuicios públicos.

Analisando os argumentos que são apresentados contra a pretensão de deixar a atenção à saúde ao livre jogo do mercado (ou se se prefere a fórmula utilizada geralmente as razóes que podem justificar a intervençâo do estado no mercado) podem ser divididas essencialmente em dois tipos: a) os que centram em ressaltar a ineficiência do mercado na área de proteçáo à saúde e b) os que se centram em ressaltar as consequências desiguais do mercado. Embora se trate de argumentos de tipos diversos, estes não são contraditórios. De outro lado, pode-se afirmar que qualquer desses argumentos possui razão suficiente para justificar o abandono do livre mercado em matéria de assistência à saúde. 
Nas razóes do tipo apresentado na letra "a”, segundo Stiglitz (1995), o mercado da assistência à saúde está muito longe das características que a teoria atribui aos mercados competitivos, posto que o mercado de saúde lida com informaçóes e competências imperfeitas e o mercado da medicina se diferencia dos mercados competitivos convencionais, ao menos porque: tem um número limitado de vendedores (poucos hospitais); não se comportam exatamente como empresas maximizadoras de benefícios; os bens que oferecem não são homogêneos; os compradores não possuem informaçóes perfeitas e completas sobre diagnósticos e tratamentos e os pacientes pagam somente uma parte do custo, pois não custeiam, por exemplo, as pesquisas científicas na área.

Além de outros fatores, a existência de informaçóes imperfeitas ou insuficientes (os pacientes somente sabem aquilo que é informado pelos médicos) e a heterogeneidade dos serviços oferecidos (a incapacidade de valorar comparativamente as distintas ofertas e serviços) reduzem o grau de análise segura das competências.

Como o mercado médico se comporta de forma distinta dos mercados convencionais, não se pode, por exemplo, garantir que o aumento do número de médicos no mercado corresponda, necessariamente, a uma diminuição dos preços (STIGLITZ, 1995).

Algumas dessas características parecem inelimináveis e devidas às características intrínsecas aos mercados de saúde, tais como: a heterogeneidade dos serviços e a informação superficial sobre doenças e tratamentos dados aos pacientes/compradores. Contudo, outras características parecem depender mais da estrutura institucional e da regulação do sistema de saúde de cada país, ou melhor, parecem ser aspectos nos quais se pode incidir de maneira mais ou menos intensa.

Assim, se poderia promover, a partir de determinados incentivos ou puniçóes, a competição entre hospitais, ou fazer com que os pacientes pagassem uma quantidade maior - ou a totalidade - dos custos da saúde. E, de fato, algumas medidas (re)privatizadoras da saúde estão neste sentido, de tentar aproximação o máximo possível ao modelo de mercado competitivo.

Deixando de lado o fato de que, como afirma Añón (2009), algumas das características intrínsecas do mercado da saúde se distanciam do modelo de mercado competitivo. O mercado competitivo ao eliminar todo tipo de benefícios fiscais, subsídios ou sistemas de proteção, faz com que os pacientes tenham somente o tipo de proteção à saúde que estejam dispostos a pagar (leia-se que podem pagar). Mas, desta maneira, como se pode perceber, a objeção não está relacionada com a eficiência, mas com os injustos e desiguais resultados produzidos e inaceitáveis.

\section{Conclusões}

Demonstrou-se a ausência de solidez das teorias negadoras. Constatou-se que o direito à saúde é um direito complexo, pois expressa uma série de elementos distintos, 
embora conectados entre si, entre os quais estão, no mínimo: o direito que tem o indivíduo de não sofrer danos em sua saúde, provocados por terceiros, sejam pessoas físicas ou jurídicas, públicas ou privadas; o direito a que o estado promova uma série de medidas e políticas de proteção e promoção da saúde pública, meio ambiente e seguridade social e que sejam criadas condiçóes para que a saúde das pessoas não seja ameaçada e o direito à assistência sanitária. Este ponto é importante, pois de alguma forma as outras condições dele derivam.

Concluiu-se que como direito à saúde abarca todos esses elementos, não resta dúvida de que esse direito deve ser concebido como universal em sua titularidade. Demonstrouse a identificação do direito à saúde ao direito à assistência à saúde. Provou-se que a redução do direito à saúde ao direito à assistência à saúde não afeta sua universalidade. Percebeu-se que o direito à saúde não se identifica meramente com um direito de negação, ou seja, com o direito de o indivíduo não ser lesado em sua saúde. Examinou-se que essa perspectiva é uma parte do direito à saúde - conectada com outros direitos, como o direito a integridade física, ou o direito à vida - mas não a única.

Comprovou-se que é possível falar da existência de um direito à saúde, em oposição às teorias negadoras em dupla perspectiva: do direito à saúde do ponto de vista jurídico e de sua justificação atendendo a considerações metajurídicas. Analisaram-se as teorias de negaçáo do direito à saúde desenvolvidas a partir de uma proposta que se apresenta como libertariana.

Problematizou-se a perspectiva restritiva de admitir o dever de custear a assistência à saúde de um indivíduo apenas no caso de o estado ou terceiro ter provocado diretamente o dano à saúde daquele, ou seja, o direito de assistência à saúde surgir apenas como uma compensação ou reparação à violação do direito à vida ou à integridade física do sujeito. Questionou-se a ideia das teorias negadoras de que o valor supremo a defender é a liberdade individual e de que os únicos direitos legítimos sejam os direitos de não interferência, que protegem a esfera da individualidade. Analisou-se a perspectiva do Estado Mínimo para advertir que essa proposta está preocupada apenas com a proteção dos direitos de liberdade e propriedade e que náo pode ser caracterizada como uma opção atualizada de estado.

Desconstruiu-se a teoria das loterias natural e social, pois entende-se que não parece ser legítimo operar uma completa naturalizaçáo das desigualdades, embora o fato de que uma pessoa possa nascer no seio de uma família rica ou pobre possa se configurar como uma questão do acaso. No entanto, não é uma questão do acaso que existam famílias ricas e pobres, também não é uma questão do acaso que existam desigualdades sociais ou que essas desigualdades sejam tão abissais.

Evidenciou-se que, exceto a particular visão libertariana, não parece contrário à concepção liberal (de respeito à autonomia) o fato de que a desigual distribuição dos bens 
sociais seja temática imprescindível e extremamente relevante para consecução do ideal de justiça, bem como necessidade de consecução de certas medidas de correção social sustentadas em direitos, caracterizados como fundamentais.

Criticou-se a proposta do mínimo decente e do dever de beneficência, por entender que não é uma derivação de um princípio de justiça e muito menos uma derivação de um direito individual à proteção à saúde. Questionou-se a suposição de que o mercado possa fazer uma distribuição de recursos sanitários eficiente e justa. Observou-se que as políticas públicas em matéria de saúde e o reconhecimento de um direito à saúde, postas em marcha nos sistemas sanitários de caráter público, resultam da histórica constatação de que as injustiças e as desigualdades existentes, no que se refere à proteção da saúde, não podem ser solucionadas unicamente por critérios mercadológicos.

O mercado competitivo ao eliminar todo tipo de benefícios fiscais, subsídios ou sistemas de proteção, faz com que os pacientes tenham somente o tipo de proteção à saúde que estejam dispostos a pagar (leia-se que podem pagar). Mas, desta maneira, como se pôde perceber, a objeção não está relacionada com a eficiência, mas com os injustos e desiguais resultados produzidos e inaceitáveis.

\section{Referências}

AMOEDO SOUTO, Carlos. Poder policial y derecho administrativo. A Coruña: Universidad da Coruña, 2000.

AÑÓN, Lema Carlos. Salud, justicia, derechos: el derecho a la salud como derecho social. Madrid: DYKINSON, 2009.

ARNSPERGER, C.; VAN PARIJS, P. H. Ética económica y social: teorías de la sociedad justa. Barcelona: Paidós: 2002.

BEAUCHAMP, D. E.; STEINBOC, B. (Ed.). New ethics for the public's health. New York: Oxford University Press, 1999.

BERLINGUER, G. Bioética cotidiana. México: Siglo XXI, 2002.

BUCHANAN, Allen E. A right to a decent minimum of health care. Philosophy and Public Affairs, v. 13, 1984.

COBREROS MENDAZONA, Eduardo. Los tratamientos sanitarios obligatorios y el derecho a la salud. Oñati: Instituti Vasco de Administración Pública, 1988.

CORTINA, Adela. Ética, tecnología y salud. In: CALVENTE, Maria García. Ética y salud. Granada: Escuela Andaluza de Salud Pública, 1998.

DALLARI, Sueli Gandolfi; NUNES JÚNIOR, Vidal Serrano. Direito sanitário. São Paulo: Verbatim, 2010. 
ENGELHARDT, H. Tristan. Los fundamentos de la bioética. Barcelona: Paidós, 1995.

FERNÁNDEZ, E. Estado, sociedad civil y democracia, em AAVV: valores, derechos y Estado a finales del siglo XX. Madrid: Marcial Pons, 1995

GAVÍN, Juan Pemán. Derecho a la salud y administración sanitaria. Bolonia: Publicaciones del Real Colegio de España, 1989.

GONZÁLEZ, Àngel Puyol. Ética, derechos y racionamiento sanitario. Doxa: Cuadernos de Filosofía del Derecho, n. 22, 1999.

GRACIA, Diego. Fundamentos de bioética. Madrid: Eudema, 1988.

HIERRO, Liborio. Justicia, igualdad y eficiência. Madrid: Centro de Estudos Políticos y Constitucionales, 2002.

NOZICK, Robert. Anarquía, Estado y utopía. México: FCE, 1990.

. Anarquia, estado e utopia. Rio de Janeiro: Zahar, 1991.

OMS. Constituição da Organização Mundial de Saúde. 1946. Disponível em: <http:// www.fd.uc.pt/CI/CEE/OI/OMS/OMS.htm>. Acesso em: $10 \mathrm{dez} .2010$.

RAWLS, John. Uma teoria da justiça. Trad. Vamireh Chacon. Brasília, DF: Unb, 1981. (Coleção Pensamento Político, 50).

STIGLITZ, Joseph Eugene. Le economia del setor público.Barcelona: Bosch, 1995.

TOEBES, Brigit. The right to health. In: EIDE, A.; KRAUSE, C.; ROSAS, A. (Ed.). Economic social and cultural rights. A textbook. 2nd. rev. Boston: London: Martinus Nijhoff Publishers, 2001.

VIDIELLA, Graciela. El derecho a la salud. Buenos Aires: Eudeba, 2000.

VITA, Alvaro. Liberalismo, Justiça Social e Responsabilidade Individual. DADOS- Revista de Ciências Sociais, Rio de Janeiro, vol. 54, no 4, 2011, pp. 569 a 608. 